\title{
Transcriptomic Analysis in Liquid Biopsy Identifies Circulating PCTAIRE-1 mRNA as a Biomarker in NSCLC
}

\author{
JOHN WEN-CHENG CHANG ${ }^{1,2 \#}$, CHUN-LIANG SHIH ${ }^{3 \#, ~ C H I H-L I A N G ~ W A N G ~}{ }^{2,4}$, JI-DUNG LUO $^{3,5}$, \\ CHIH-WEI WANG ${ }^{6}$, JIA-JUAN HSIEH ${ }^{1}$, CHIA-JUNG YU $^{3,4,7}$ and CHIUAN-CHIAN CHIOU ${ }^{3,4,8}$ \\ ${ }^{1}$ Division of Hematology-Oncology, Department of Internal Medicine, \\ Chang Gung Memorial Hospital, Taoyuan, Taiwan, R.O.C.; \\ ${ }^{2}$ College of Medicine, Chang Gung University, Taoyuan, Taiwan, R.O.C.; \\ ${ }^{3}$ Graduate Institute of Biomedical Sciences, College of Medicine, Chang Gung University, Taoyuan, Taiwan, R.O.C.; \\ 4Department of Thoracic Medicine, Chang Gung Memorial Hospital, Taoyuan, Taiwan, R.O.C.; \\ ${ }^{5}$ Bioinformatics Resource Center, The Rockefeller University, New York, NY, U.S.A.; \\ ${ }^{6}$ Department of Anatomic Pathology, Chang Gung Memorial Hospital, Taoyuan, Taiwan, R.O.C.; \\ ${ }^{7}$ Department of Cell and Molecular Biology, College of Medicine, \\ Chang Gung University, Taoyuan, Taiwan, R.O.C.; \\ ${ }^{8}$ Department of Medical Biotechnology and Laboratory Science, \\ College of Medicine, Chang Gung University, Taoyuan, Taiwan, R.O.C.
}

\begin{abstract}
Background/Aim: Circulating $m R N A$ can be a useful source of cancer biomarkers. We took advantage of direct transcriptomic analysis in plasma RNA to identify novel mRNA markers for non-small cell lung cancer (NSCLC). Patients and Methods: Plasma RNA from NSCLC patients and healthy individuals was profiled with cDNAmediated annealing, selection, extension and ligation (DASL) microarrays. The microarray results were further validated in plasma RNA. Results: Through RNA profiling and online database mining, four gene transcripts were filtered as candidate markers of NSCLC. After validation, the PCTAIRE-1 transcript was identified as a circulating $m R N A$ marker. The diagnostic potential of PCTAIRE-1 was evaluated by receiver operating characteristic curve analysis, which gave a sensitivity and specificity of $60 \%$ and $85 \%$, respectively. In addition, high plasma PCTK1 levels were also correlated with poor progression-free survival
\end{abstract}

This article is freely accessible online.

\footnotetext{
\#These Authors contributed equally to this study.

Correspondence to: Dr. Chiuan-Chian Chiou, Department of Medical Biotechnology and Laboratory Science, Chang Gung University, 259 Wenhwa 1st Road, Kweishan, Taoyuan 333, Taiwan, R.O.C. Tel: +88632118800 ext 5204, Fax: +88632118035 , e-mail: ccchiou@mail.cgu.edu.tw
}

Key Words: PCTK1/CDK16, biomarker, non-small cell lung cancer, circulating mRNA. (p=0.008). Conclusion: Circulating mRNA can be profiled with the DASL assay. From the profile, PCTAIRE-1 RNA in the plasma we discovered as a novel diagnostic/prognostic biomarker and an indicator of poor survival in NSCLC patients.

The detection of biomarkers in liquid biopsy (i.e., in body fluids) is valuable for the diagnosis and prognosis of malignant diseases, as its sampling is less invasive and can be carried out repeatedly. Some well-known circulating cancer markers, including CEA, PSA, CA125, and CA153, are proteins. These markers do not have sufficient sensitivity and specificity for detecting certain cancers [e.g., non-small cell lung cancer (NSCLC)]. The identification of novel biomarkers in these cancers is thus in great demand. In addition to protein markers, circulating nucleic acids are promising sources for new biomarkers, as circulating nucleic acids provide information regarding the genome or gene expression. In addition, some well-developed technologies, such as polymerase chain reaction (PCR) and highthroughput sequencing, can detect traces of nucleic acids in the circulation, allowing the usage of nucleic acid markers.

Different species of circulating nucleic acid markers, including cell-free DNA (cfDNA), microRNA (miRNA) (14), long noncoding RNA (lncRNA) (4-8), and mRNA (9), have been linked with malignant diseases. Among them, mRNA is one of the least investigated species (9). Until now, only a few circulating mRNA markers have been reported. For example, tyrosinase mRNA can be detected in the blood of some melanoma patients (10); telomerase mRNAs can be 
detected in breast cancer patients (11), CK19, mammaglobin, 5T4, and circulating thyroid-stimulating hormone receptor (TSHR) mRNAs can be detected in thyroid cancer patients (12); 5T4 mRNA can be detected in lung cancer patients (13); and CEA and CK19 mRNAs can be detected in colorectal cancer patients (14). These studies have revealed that circulating mRNAs can be potential biomarkers.

A difficulty in identifying circulating mRNA markers is that the RNA profile in plasma is different from that in tumor tissues. As blood is rich in background RNA from the whole body, most RNA markers found in tumor tissues may be masked by the background and cannot be used. A highthroughput analysis in blood samples could be directly used to discover mRNA markers that are not masked. Another difficulty is that mRNA in plasma is usually fragmented and found at a low abundance. A special amplification technology is required to enrich its amount before conducting subsequent analyses. In our previous study, we have shown that circulating mRNA could be amplified and profiled using the cDNA-mediated annealing, selection, extension, and ligation (DASL) assay (15). In the current study, we applied the DASL assay to identify novel circulating mRNA biomarkers in NSCLC patients.

PCTAIRE-1 (PCTK1), also known as cyclin-dependent kinase 16 (CDK16), belongs to the PCTAIRE family, which comprises a conserved central kinase domain with an amino acid sequence highly similar to that of CDK family members (16). PCTK1 is highly expressed in the brain and testis but not in other tissues (17-20). PCTK1 is involved in a wide range of biological functions, including neurite outgrowth (21), spermatogenesis $(22)$, secretory transport $(23,24)$ and insulin secretion (25). Recently, few studies have revealed the involvement of PCTK1 in cell proliferation or antiapoptosis in several types of malignancies $(26,27)$.

In this study, we found that the levels of PCTK1 RNA are high in the plasma of NSCLC patients. We also demonstrated that high levels of PCTK1 RNA are correlated with poor survival. NSCLC is the most common type of lung cancer cases and an important cause of death worldwide (28-31). The development of diagnostic and prognostic biomarkers will be helpful in cancer management. The identification of circulating PCTK1 as a novel mRNA biomarker for NSCLC is valuable for the future development of diagnostic or monitoring tools.

\section{Patients and Methods}

Patient samples and plasma collection. Forty-three NSCLC patients were recruited from the Chang Gang Memorial Hospital. Another forty-three healthy controls were recruited from the Health Check Center of the same hospital. Written informed consent from each patient was obtained before sample collection. This study was approved by the Chang Gung Memorial Hospital Institution Review Board (with approval numbers 100-2065A3, 102-1749C, 102-
1584C1, 103-7926C1, and 104-7490D). The clinical stage of each patient was classified according to the AJCC staging system. All participants were divided into two groups. Five patients ( 1 male and 4 females, ranging from 49 to 90 years of age, mean age: $69.2 \pm 14.9$ ) with primary stage IV NSCLC and six healthy individuals ( 2 males and 4 females, ranging from 56 to 61 years of age, mean age: $58.1 \pm 1.7)$ were enlisted in the discovery phase. The NSCLC patients provided blood samples before (Nontreatment group) and two weeks after the first treatment with chemotherapy or targeted therapy (Treatment group). The control individuals provided blood samples once (Healthy group). Thirty-eight treatment-naive patients with non-small cell lung cancer regardless of stage (21 males and 17 females, ranging from 38 to 81 years of age, mean age: $61.7 \pm 12.2$ years) and thirty-seven healthy individuals with a similar distribution of age (28 males and 5 females, ranging from 53 to 79 years of age, mean age: $62.9 \pm 7.7$ years) were enrolled in the validation phase. Peripheral blood from the participants was collected into an EDTA tube and centrifuged at $1600 \times g$ for $10 \mathrm{~min}$ at room temperature. The supernatants (plasma) were separated and stored at $-80^{\circ} \mathrm{C}$ until further processing.

Isolation of circulating $m R N A s$. Total RNA was extracted from plasma using TRIzol LS reagent (Thermo Fisher Scientific, Waltham, MA, USA) according to the manufacturer's instructions. In the discovery phase, RNA from each sample was extracted from $5 \mathrm{ml}$ plasma. In the validation phase, RNA was extracted from $250 \mu$ plasma. Briefly, a 250- $\mu$ l plasma aliquot was mixed with one milliliter TRIzol LS reagent. After $5 \mathrm{~min}$ of incubation, $266 \mu \mathrm{l}$ of chloroform was added to the mixture. Then, the mixture was centrifuged at $14000 \times g$ for $15 \mathrm{~min}$ at $4^{\circ} \mathrm{C}$. The aqueous layer was transferred to a new tube. An equal volume of isopropanol and $1 \mu \mathrm{l}$ GlycoBlue (Thermo Fisher Scientific) was added to the solution to precipitate RNA. The solution was further centrifuged at $14000 \times g$ for $15 \mathrm{~min}$ at $4^{\circ} \mathrm{C}$. The RNA pellet was washed with cold $70 \%$ ethanol, air dried for $10 \mathrm{~min}$, and resuspended in $30 \mu \mathrm{l}$ DEPC-treated water at $56^{\circ} \mathrm{C}$ for $10 \mathrm{~min}$. RNA concentration was estimated with a Nanodrop ND-1000 (Thermo Fisher Scientific) and the RiboGreen RNA assay on a Qubit fluorescence reader (Thermo Fisher Scientific).

Microarray analysis for circulating mRNA profiling. The DASL assay (Illumina, San Diego, CA, USA) was used to preamplify and label the mRNA transcripts from plasma samples. The pre-amplified cDNA products were then hybridized to a Human HT-12 v4 Expression BeadChip (Illumina), which contains probes for 23,811 coding transcripts. The DASL assay and expression profiling experiments were performed at Genetech Biotech (Taipei, Taiwan). Raw data were processed using Partek Genomic Suite (PGS) software (St. Louis, MO, USA) for bioinformatics analysis (32). The similarities and differences in circulating mRNA profiles between NSCLC patients and healthy controls were assessed by using principal component analysis (PCA) and hierarchical clustering, which group samples according to their expression features. Hierarchical clustering was performed with the Euclidean and Pearson's dissimilarity algorithms. The differentially expressed genes were selected for further analysis if they met the following criteria: genes that were not low in abundance or with an abnormal pattern in all samples; genes whose average expression levels between patients and controls were significantly different (with $p<0.05$ ) in one-way ANOVA; and genes whose mean expression levels in one group was at least two-fold greater than that in the other group. 
Online database mining. To confirm the differentially expressed genes that had also been identified in lung tissue mRNA profiles, the selected genes were then filtered in the Oncomine database (http://www.oncomine.org) $(33,34)$. In the Oncomine search for gene expression (cancer $v s$. normal), a fold change above 1.5 and a $p$-value below 0.05 were set as the thresholds.

Reverse transcription quantitative PCR (RT-qPCR). To quantify the target mRNA level, the extracted RNA was reverse transcribed into cDNA with MMLV reverse transcriptase (Promega, Madison, WI, USA). Then, $2 \mu \mathrm{l}$ of the cDNA was used as a template for qPCR, which included Platinum Taq polymerase and its reaction buffer (Thermo Fisher Scientific), 4 dNTPs, primers, and SYBR Green I. qPCR was performed in triplicate with the following thermal cycling conditions: incubation at $95^{\circ} \mathrm{C}$ for $3 \mathrm{~min}$, followed by 45 thermal cycles $\left(95^{\circ} \mathrm{C}\right.$ for $15 \mathrm{sec}, 60^{\circ} \mathrm{C}$ for $30 \mathrm{sec}$ and $72^{\circ} \mathrm{C}$ for $30 \mathrm{sec}$ ), and a final incubation at $72^{\circ} \mathrm{C}$ for $3 \mathrm{~min}$. The fluorescent signals were detected at each cycle at $60^{\circ} \mathrm{C}$, which generated an amplification curve of each reaction. The relative level of a target gene to a housekeeping gene, $\beta 2$-microglobulin (B2M), was calculated from their threshold cycle $(\mathrm{Ct})$ with the equation $2^{\wedge}\left(\mathrm{Ct}_{\mathrm{B} 2 \mathrm{M}}-\mathrm{Ct}_{\text {gene }}\right)$. The primer sequences for PCTK1 were 5'-GTCAGCCTATCTGAGATTGG-3' (forward) and 5'-TTCATATTCCAGTCTGATCTC-3' (reverse). Those for B2M were 5'-CATTCAGACTTGTCTTTCAG-3' (forward) and 5'TTCAAACCTCCATGATGC-3' (reverse).

Immunohistochemical staining. The formalin-fixed, paraffin-embedded (FFPE) tissue sections from NSCLC patients were obtained from the Tissue Bank in Chang Gung Memorial Hospital. One of the serial sections was stained with hematoxylin and eosin to identify the most representative regions of the tumor. Immunohistochemistry was performed according to a protocol from Abcam (https://www.abcam.com/ps/pdf/protocols/ ihc_p.pdf), with slight modifications. Briefly, the tissue section was first treated with heated $0.01 \mathrm{M}$ citrate buffer ( $\mathrm{pH}$ 6.0) to retrieve antigens, then soaked in $3 \% \mathrm{H}_{2} \mathrm{O}_{2}$ to inactivate endogenous peroxidase, and in Antibody Diluent solution (Dako, Glostrup, Denmark) to block nonspecific signals. Then, samples were incubated with antibodies against the PCTK1 protein (1:200 dilution; HPA 001366, Sigma-Aldrich, St. Louis, MO, USA) overnight at $4^{\circ} \mathrm{C}$ and then with anti-rabbit antibodies conjugated with horseradish peroxidase (1:250 dilution; Calbiochem, Darmstadt, Germany) for $60 \mathrm{~min}$ at room temperature. Color was revealed by treatment with DAB chromogen (DAKO) and hematoxylin. The slides were scored for PCTK1 staining under the microscope by a senior pathologist without knowledge of the patients' histories. The PCTK1 score was calculated according to a simplified $\mathrm{H}$ score system (35) based on the percentage of stained cells $(3,>90 \% ; 2,50-89 \% ; 1,10-49 \%$; and $0,0-9 \%)$ and the intensity of staining ( 3 , strong; 2 , moderate; 1 , weak; or 0 , none). The two scores were multiplied by each other and divided by 3 to obtain the final score. Positive staining was defined as a final score $\geq 1$.

Statistical analysis. Statistical analysis was conducted with SPSS software for Windows version 17.0 (SPSS, Inc., Chicago, IL, USA). A nonparametric Mann-Whitney test was used to compare gene expression levels or IHC scores between different groups. Receiver operating characteristic (ROC) curve and area under curve analyses were used to estimate the discriminative power and determine the cutoff value of the PCTK1 RNA level in specimens. A chi-square test was used to determine the association between circulating PCTK1 levels and clinical-pathological characteristics. The survival curves were plotted with the Kaplan-Meier method and analyzed using the log-rank test. A $p$-value $\leq 0.05$ was regarded as statistically significant.

\section{Results}

Experimental design. The aim of this study was to identify circulating mRNA markers of NSCLC. The study design included a discovery phase and a validation phase. The whole experimental strategy is simplified in a flow chart in Figure 1.

Circulating mRNA profiling in the discovery phase. Five NSCLC patients and six healthy controls were included in the discovery phase. The NSCLC patients provided blood samples before (Nontreatment group) and two weeks after the first treatment with chemotherapy or targeted therapy (Treatment group). The control individuals provided blood samples once (Healthy group). RNA was extracted from the samples and profiled with the DASL assay and an HT-12 bead-based microarray, which were designed to amplify fragmented RNA. The microarray detected approximately 15,000 genes in the plasma RNA of each sample. There was no significant difference in the number of detected genes or the average intensity between samples or between groups. PCA plots demonstrated that the NSCLC patients were grouped together and distinguished from healthy controls (Figure 2A). Hierarchical clustering also confirmed that the NSCLC patients were clustered apart from the healthy controls (Figure 2B). However, in the same patient, the plasma RNA profiles before and after treatment were not significantly different.

Selection of candidate genes. We then selected genes whose levels were elevated in the NSCLC patients by comparing the profiles of the Nontreatment group and the Healthy group (the criteria are detailed in the Materials and Methods section). Ninety-nine genes were selected at this stage (not shown). We then determined the levels of these genes in lung cancer tissues in the Oncomine database. Only four genes revealed pronounced elevation in most analyses in the dataset: MAP1B, MMP1, PCTK1 and PTPRF. We then determined the circulating mRNA levels of the four genes in the validation cohort, including 75 plasma samples (38 from NSCLC patients and 37 from healthy controls). Among the four candidate genes, only PCTK1 demonstrated significant elevation in patients' plasma (Figure 3A).

Diagnostic and prognostic value of circulating PCTK1 RNA. A ROC curve was applied to test the ability of PCTK1 RNA in the diagnosis of NSCLC. When the optimal threshold was set, the area under the ROC curve was 0.7745 , giving a sensitivity and specificity of $60 \%$ and $85 \%$, respectively (Figure 3B). Based on this threshold, the patients were divided into two groups: PCTK1-high and PCTK1-low. In the survival analysis, the PCTK1-high group had significantly $(p=0.008)$ shorter progression-free survival (PFS) (mean=5.5 months) than the PCTK1-low group (mean=14.3 months) in the log-rank test 


\section{Discovery phase}

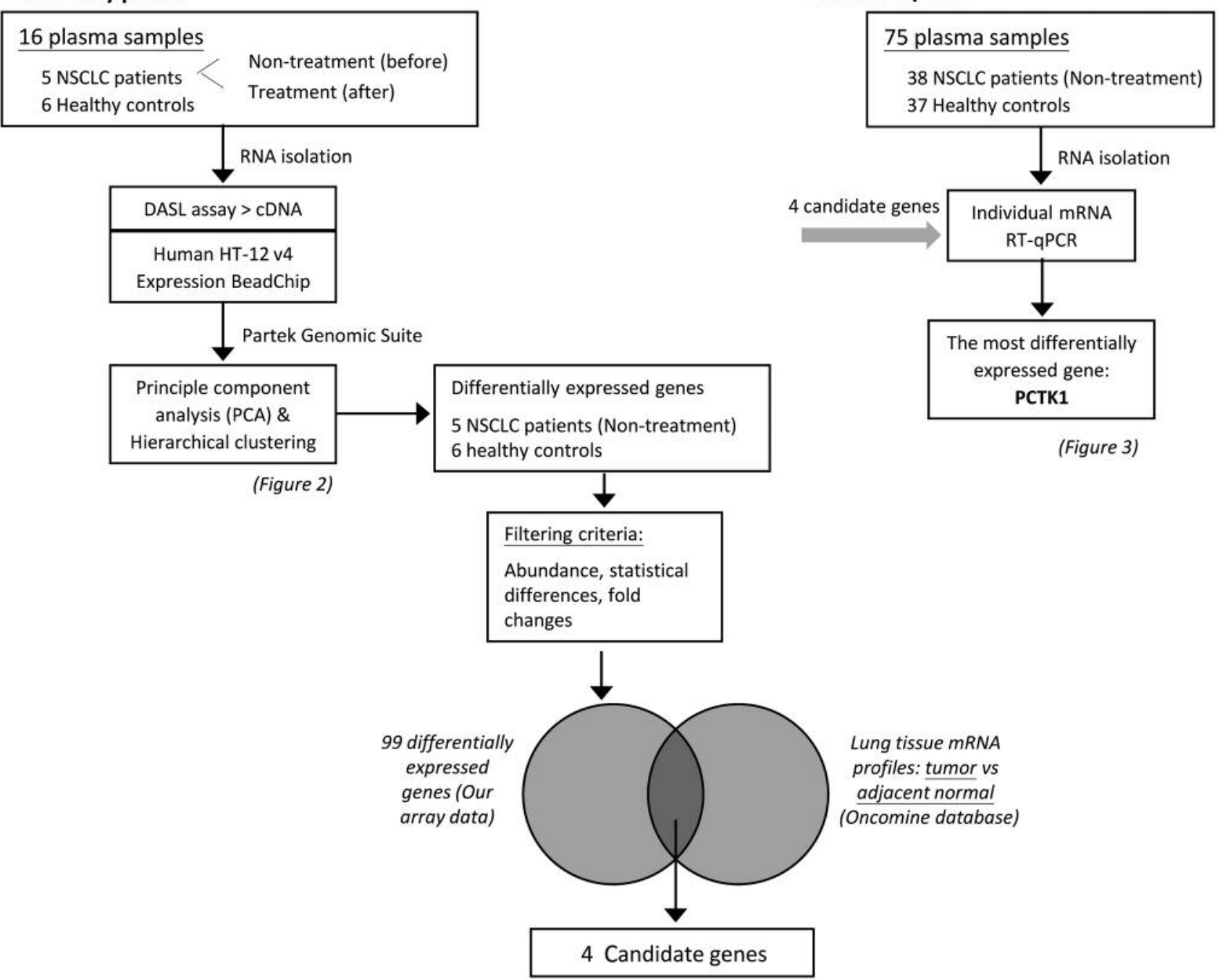

Figure 1. Diagram of the study design, clinical sample flow, and process of candidate gene evaluation.

(Figure 4A). The PCTK1-high group also had shorter OS (mean=22.7 months) than the PCTK1-low group (mean=55.5 months), although the difference was not statistically significant $(p=0.195)$ (Figure 4B). In contrast, the PCTK1 levels were not associated with other clinical-pathological factors, such as age, sex, cancer stage, tumor pathology, smoking history, TKI treatment, or EGFR status (Table I).

Confirmation of PCTK1 overexpression in NSCLC tissues. Then, the PCTK1 protein levels were determined in 29 FFPE tissues from lung cancer patients. Among them, 18 were from needle biopsies, and 11 were from surgically removed tissues. Only the surgically removed tissues had an obvious normal component in the tissue sections. Immunohistochemical staining showed that cancer tissues had strong positive staining for the PCTK1 protein that was mainly cytoplasmic (Figure 5A). The $\mathrm{H}$ score also showed that the tumor tissues had significantly higher staining than the normal tissues (Figure 5B). An H score $\geq 1$ was defined as positive; $93 \%$ (27/29) of the tumor tissues were positive, but only $18 \%(2 / 11)$ of the normal tissues were positive.

\section{Discussion}

In this study, we successfully isolated and profiled circulating mRNAs from NSCLC patients by using the DASL assay. The DASL assay is specialized for the amplification of poor-quality and fragmented RNA extracted from FFPE tissues $(15,25,36,37)$. It can be adapted for the amplification of circulating mRNA in plasma samples. Through the DASL assay and online database mining, we 


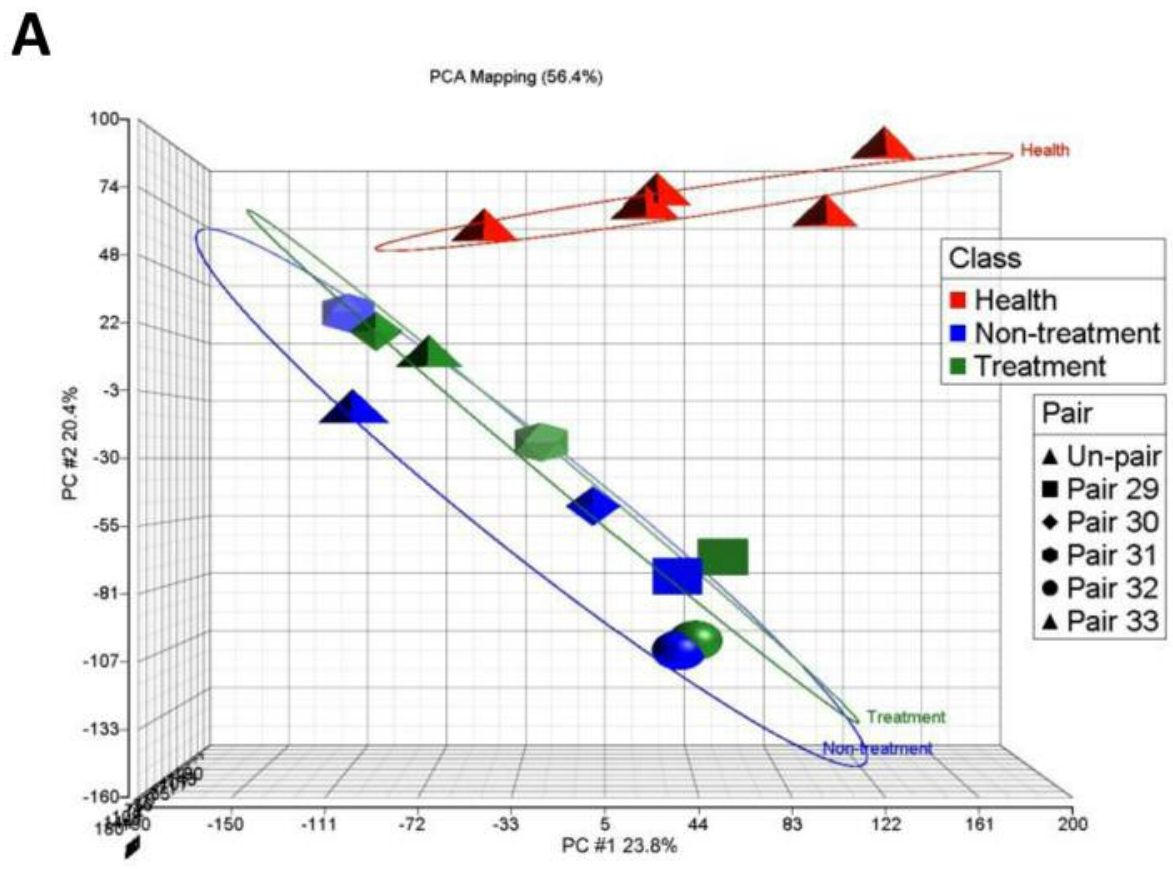

B

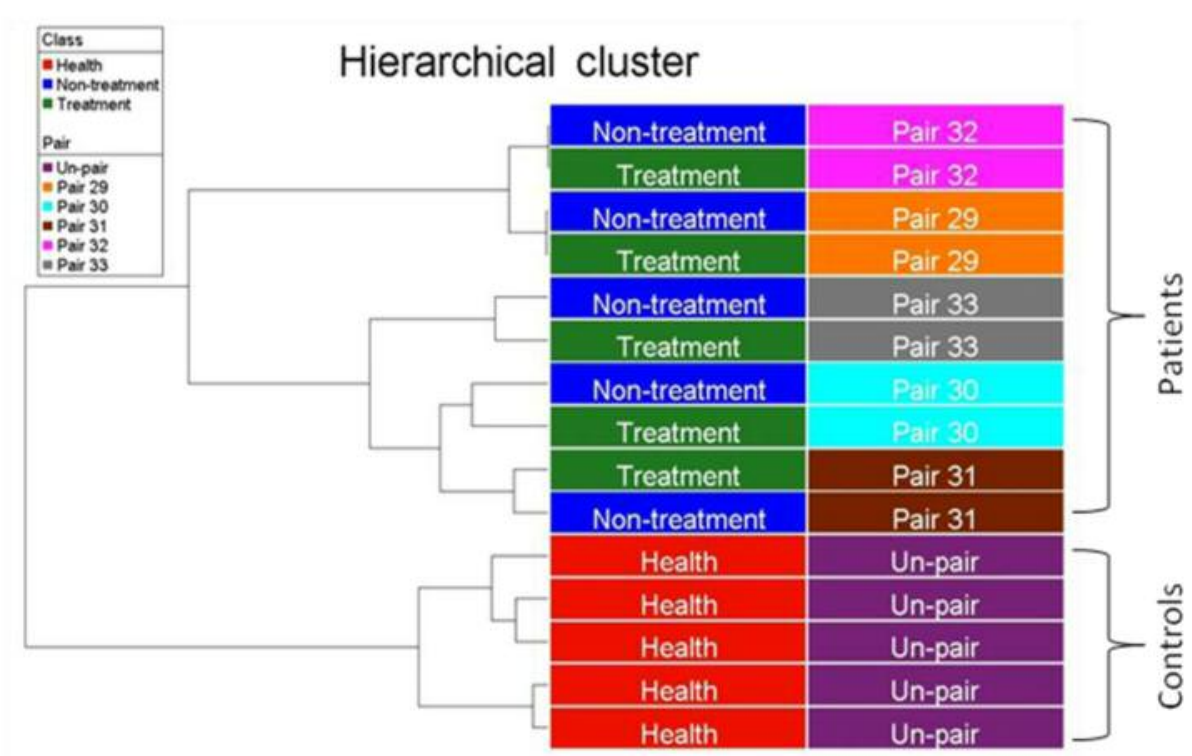

Figure 2. Profiles of circulating mRNAs distinguishing NSCLC patients from healthy controls. Transcriptomic profiles of circulating mRNAs in the plasma of NSCLC patients ( $n=5$, paired samples, including nontreatment in blue and treatment in green) and healthy controls ( $n=6$, in red) were analyzed and are presented as PCA plots $(A)$ and hierarchical clustering $(B)$. The results of PCA and hierarchical clustering demonstrate divergent patterns between NSCLC patients and healthy controls.

selected certain transcripts as candidate mRNA markers. In the subsequent validation experiments, we confirmed the elevation of PCTK1 in NSCLC patients, both in peripheral blood and in tumor tissues, and that the elevation of circulating PCTK1 RNA is associated with a poor prognosis.
RNA overexpressed in cancer tissues is not necessarily expressed at a high level in the peripheral blood. This is because the tumor mass accounts only for a small portion of the body, and both the tumor tissue and other normal tissues contribute RNAs to the circulation. Most RNAs elevated in 


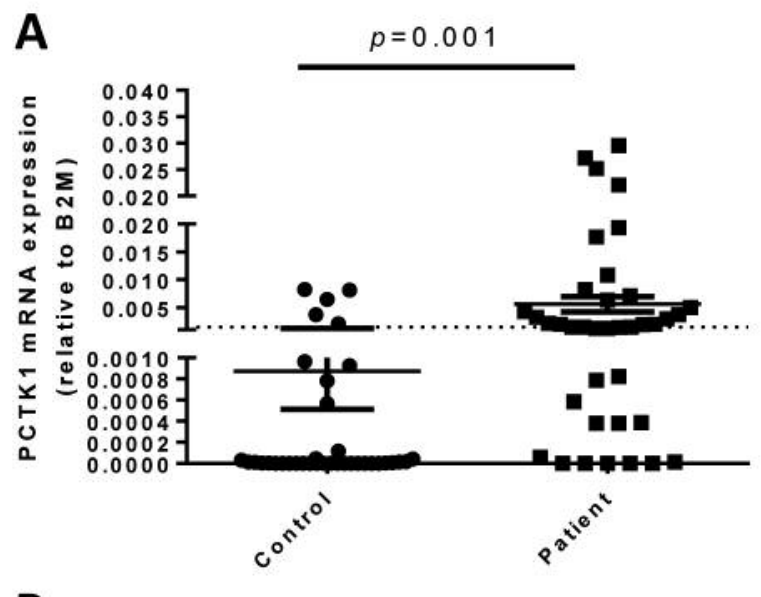

B

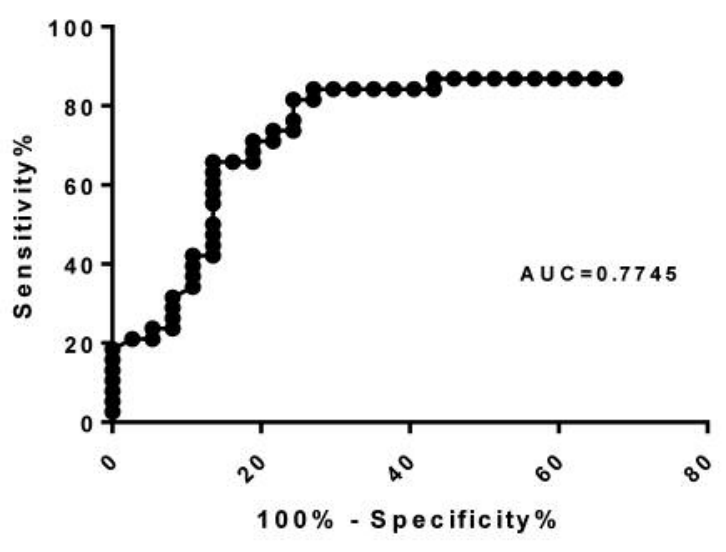

Figure 3. Identification of PCTK1 as an elevated circulating $m R N A$ in NSCLC patients. (A) The PCTK1 mRNA levels in the plasma were determined by reverse transcription quantitative $P C R$ and normalized to that of the $\beta 2$-microglobulin (B2M) transcript. (B) Receiver operating characteristic curve analysis of the diagnostic efficacy of plasma PCTK1 RNA levels.

tumor tissues are thus masked by background RNAs from normal tissues. Therefore, the RNA candidates overexpressed in tumor tissues are not necessarily good markers in the circulation. Our results confirmed this argument, as only four gene transcripts selected in the plasma matched the overexpressed genes in NSCLC tissues in the Oncomine database. Our study demonstrated that the direct profiling of circulating RNA is a feasible strategy and can be applied to biomarker selection in other diseases.

Recent studies have indicated that cells can release different particles, including exosomes (38, 39), microparticles (40) and apoptotic bodies (41). These particles are protected by the plasma membrane and are considered the major sources of circulating RNA. This notion is also confirmed by the observation that nude RNA is very unstable in the blood, which is rich in RNase activity (42).

Information about which particle PCTK1 mRNA is derived from will be helpful in the development of better diagnostic methods. For example, different methods have been developed to capture extracellular vesicles $(43,44)$. If PCTK1 mRNA exists in the captured vesicles, these technologies can be applied in the enrichment of circulating PCTK1 RNA in the detection procedure.

In current clinical practice, CEA and CYFRA21-1 are frequently used as biomarkers for the diagnosis or follow-up of NSCLC (45), but their specificity and sensitivity are not satisfactory. Over the past few years, several mRNA biomarkers circulating in peripheral blood mononuclear cells (PBMCs) for NSCLC have been reported. Some of these 
A

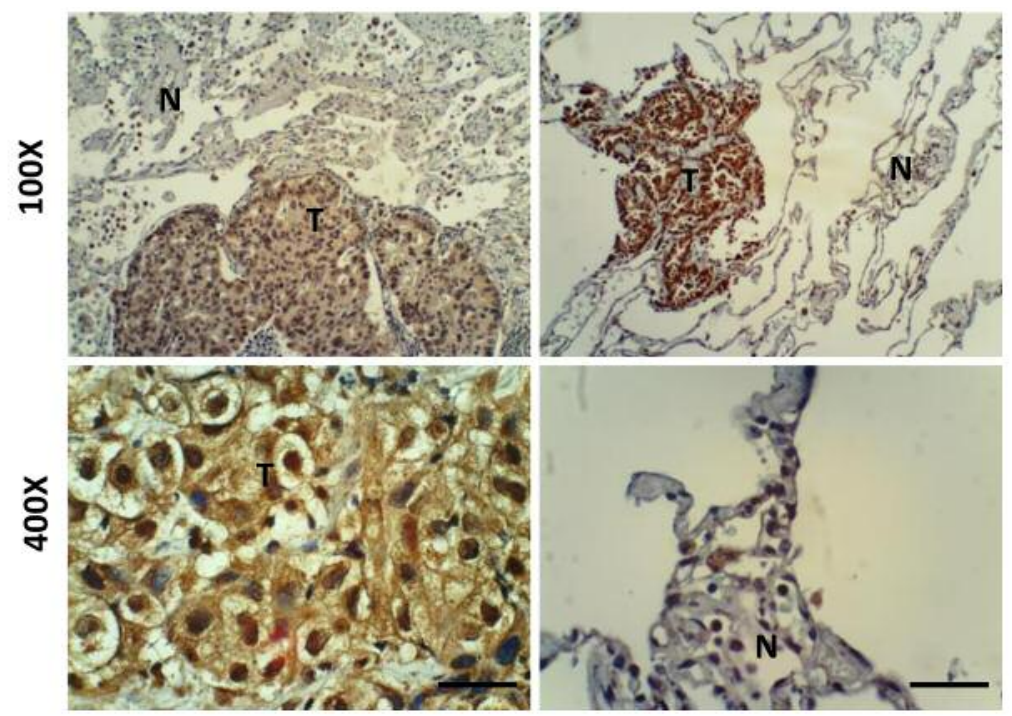

B

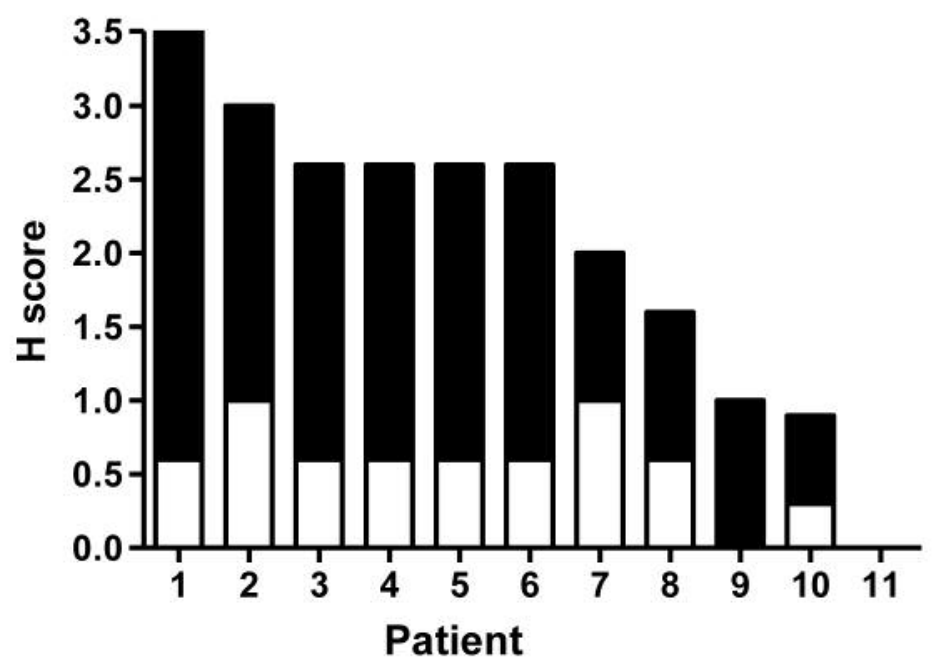

\section{Adjacent normal Lung cancer}

Figure 5. Overexpression of PCTK1 in lung adenocarcinoma tissues. The expression of PCTK1 (brown color) was investigated by immunohistochemical staining of tissue sections from formalin-fixed, paraffin-embedded NSCLC specimens. (A) Two representative immunohistochemical images (upper two images) of tumors $(T)$ surrounded with normal lung tissues $(N)$ are shown. Typical positive and negative staining was found in the carcinoma (lower left image) and normal lung tissues (lower right images), respectively. Scale bar $=50 \mu m$. (B) Bar chart analysis of the histoscores (H scores) of PCTK1 staining in 11 paired tumors and adjacent normal tissues. All the samples show positive staining except for sample number 11, which shows negative staining in both the tumor and normal tissues.

PBMC RNAs show high specificity and sensitivity in the detection of lung cancer, including angiopoietin-2 (Ang-2) (46), A-kinase anchor protein 4 (AKAP4) (47), cytokeratin 7 (CK7) (48), E74-like factor 3 (ELF3) (48), epidermal growth factor receptor (EGFR) (48), and erythropoietinproducing hepatocellular carcinoma receptor B4 (EphB4) (48). Our current study used plasma RNA instead of PBMC
RNA and discovered that PCTK1 is a newly identified plasma biomarker with $85 \%$ specificity and $60 \%$ sensitivity. In addition, a high level of PCTK1 expression is an indicator of a low survival rate. The combination of these markers and other circulating RNA species, such as miRNA or long IncRNA, may have the potential to make a marker panel for the noninvasive diagnosis or follow-up of NSCLC. 
Table I. Correlation between circulating PCTK1 mRNA levels and clinical pathologic features in the NSCLC patients.

\begin{tabular}{|c|c|c|c|c|}
\hline \multirow[t]{2}{*}{ Characteristic } & \multicolumn{3}{|c|}{ Number of patients ${ }^{a}$} & \multirow[t]{2}{*}{$p$-Value } \\
\hline & Total & PCTK1-low & PCTK1-high & \\
\hline \multicolumn{5}{|l|}{ Age (years) } \\
\hline$<65$ & 21 & 8 & 13 & \multirow[t]{2}{*}{1} \\
\hline$\geq 65$ & 17 & 7 & 10 & \\
\hline \multicolumn{5}{|l|}{ Gender } \\
\hline Female & 17 & 5 & 12 & \multirow[t]{2}{*}{0.326} \\
\hline Male & 21 & 10 & 11 & \\
\hline \multicolumn{5}{|l|}{ Stage } \\
\hline $2 \mathrm{~B}$ & 1 & 0 & 1 & \multirow[t]{3}{*}{0.407} \\
\hline $3 \mathrm{~B}$ & 5 & 3 & 2 & \\
\hline 4 & 29 & 10 & 19 & \\
\hline \multicolumn{5}{|l|}{ Pathology } \\
\hline $\mathrm{AD}$ & 34 & 13 & 21 & \multirow[t]{2}{*}{0.525} \\
\hline SCC & 2 & 0 & 2 & \\
\hline \multicolumn{5}{|c|}{ Smoking history } \\
\hline No & 24 & 8 & 16 & \multirow[t]{2}{*}{0.492} \\
\hline Yes & 14 & 7 & 7 & \\
\hline \multicolumn{5}{|l|}{ TKI } \\
\hline No & 22 & 6 & 16 & \multirow[t]{2}{*}{0.683} \\
\hline Yes & 10 & 4 & 6 & \\
\hline \multicolumn{5}{|l|}{ EGFR } \\
\hline Wild-type & 12 & 2 & 10 & \multirow[t]{2}{*}{0.217} \\
\hline Mutant & 15 & 7 & 8 & \\
\hline
\end{tabular}

aThe cut-off value is set with sensitivity of $60 \%$ and specificity of $85 \%$. The $p$-value is the probability for a Chi-square test. AD: Adenocarcinoma; SCC: squamous cell carcinoma; TKI: tyrosine kinase inhibitor treatment; EGFR: epithelial growth factor receptor.

PCTK1 is a cyclin-dependent kinase-related kinase that is involved in cell cycle regulation. Initially, PCTK1 has been reported to participate in neurite outgrowth (21) and spermatogenesis (22). However, some studies have discovered its modulatory role in protein exocytosis (24) and the export of secretory proteins from the endoplasmic reticulum to the Golgi apparatus (23). In recent years, several lines of evidence have shown that PCTK1 is involved in various human cancers, such as liver (49), colon, breast and prostate cancers and malignant melanoma $(27,50,51)$. Specifically, Wang et al. have found that PCTK1 is overexpressed in NSCLC and plays a role in cancer cell growth and anti-apoptosis (26). Our finding that PCTK1 is upregulated in lung cancer tissues confirmed their observation. These findings together specify the notable role of PCTK1 in promoting tumorigenesis and make it a potential target for cancer treatment.

\section{Conclusion}

Our study demonstrated a strategy for discovering circulating RNA markers and provided a novel biomarker: plasma PCTK1 mRNA. This biomarker can be valuable for the diagnosis/prognosis of NSCLC, and the PCTK1 gene may also be a potential therapeutic target.

\section{Conflicts of Interest}

The Authors declare no competing financial interests regarding this study.

\section{Authors' Contributions}

Conceived and designed the experiments: CC Chiou and J Chang. Conducted the experiments: CL Shih, CL Wang, JD Luo, and JJ Hsieh. Analyzed the data: CC Chiou, J Chang, CW Wang, and CJ Yu. Wrote the paper: CC Chiou.

\section{Acknowledgements}

This research was supported by the grants from Chang Gung Memorial Hospital (CMRPD1C0321-3, CMRPD1B0091-3, and CMRPG3A0661). The Authors thank Miss Zi-Ming Huang for the assistance of preparing the manuscript.

\section{References}

1 Imaoka H, Toiyama Y, Fujikawa H, Hiro J, Saigusa S, Tanaka K, Inoue Y, Mohri Y, Mori T, Kato T, Toden S, Goel A and Kusunoki M: Circulating microRNA-1290 as a novel diagnostic and prognostic biomarker in human colorectal cancer. Ann Oncol 27(10): 1879-1886, 2016. PMID: 27502702. DOI: 10.1093/annonc/mdw279

2 Tsukamoto M, Iinuma H, Yagi T, Matsuda K and Hashiguchi Y: Circulating exosomal microRNA-2 1 as a biomarker in each tumor stage of colorectal cancer. Oncology 92(6): 360-370, 2017. PMID: 28376502. DOI: 10.1159/000463387

3 Zhu T, Gao W, Chen X, Zhang Y, Wu M, Zhang P and Wang S: A pilot study of circulating microRNA-125b as a diagnostic and prognostic biomarker for epithelial ovarian cancer. Int J Gynecol Cancer 27(1): 3-10, 2017. PMID: 27636713. DOI: 10.1097/ IGC.0000000000000846

4 Gilad S, Meiri E, Yogev Y, Benjamin S, Lebanony D, Yerushalmi N, Benjamin H, Kushnir M, Cholakh H, Melamed N, Bentwich Z, Hod M, Goren Y and Chajut A: Serum microRNAs are promising novel biomarkers. PLoS One 3(9): e3148, 2008. PMID: 18773077. DOI: 10.1371/journal.pone. 0003148

5 Tan Q, Zuo J, Qiu S, Yu Y, Zhou H, Li N, Wang H, Liang C, Yu $\mathrm{M}$ and Tu J: Identification of circulating long non-coding RNA GAS5 as a potential biomarker for non-small cell lung cancer diagnosisnon-small cell lung cancer, long non-coding rna, plasma, GAS5, biomarker. Int J Oncol 50(5): 1729-1738, 2017. PMID: 28339045. DOI: 10.3892/ijo.2017.3925

6 Li N, Wang Y, Liu X, Luo P, Jing W, Zhu M and Tu J: Identification of circulating long noncoding RNA HOTAIR as a novel biomarker for diagnosis and monitoring of non-small cell lung cancer. Technol Cancer Res Treat 16(6): 1060-1066, 2017. PMID: 28784052. DOI: 10.1177/1533034617723754

7 Tang Q, Ni Z, Cheng Z, Xu J, Yu H and Yin P: Three circulating long non-coding RNAs act as biomarkers for predicting NSCLC. 
Cell Physiol Biochem 37(3): 1002-1009, 2015. PMID: 26393913. DOI: $10.1159 / 000430226$

8 Wen JJ, Ma YD, Yang GS and Wang GM: Analysis of circulating long non-coding RNA UCA1 as potential biomarkers for diagnosis and prognosis of osteosarcoma. Eur Rev Med Pharmacol Sci 21(3): 498-503, 2017. PMID: 28239821.

9 Otandault A, Anker P, Al Amir Dache Z, Guillaumon V, Meddeb R, Pastor B, Pisareva E, Sanchez C, Tanos R, Tousch G, Schwarzenbach $\mathrm{H}$ and Thierry AR: Recent advances in circulating nucleic acids in oncology. Ann Oncol 30(3): 374-384, 2019. PMID: 30753271. DOI: 10.1093/annonc/mdz031

10 Kopreski MS, Benko FA, Kwak LW and Gocke CD: Detection of tumor messenger RNA in the serum of patients with malignant melanoma. Clin Cancer Res 5(8): 1961-1965, 1999. PMID: 10473072.

11 Chen XQ, Bonnefoi H, Pelte MF, Lyautey J, Lederrey C, Movarekhi S, Schaeffer P, Mulcahy HE, Meyer P, Stroun M and Anker P: Telomerase RNA as a detection marker in the serum of breast cancer patients. Clin Cancer Res 6(10): 3823-3826, 2000. PMID: 11051224.

12 Zhang ZZ, Chen Q, Kong CY, Li ZM and Wang LS: Circulating thyroid stimulating hormone receptor messenger RNA and differentiated thyroid cancer: A diagnostic meta-analysis. Oncotarget 8(4): 6623-6629, 2017. PMID: 28036261. DOI: 10.18632 /oncotarget.14251

13 Kopreski MS, Benko FA and Gocke CD: Circulating RNA as a tumor marker: Detection of 5T4 mRNA in breast and lung cancer patient serum. Ann N Y Acad Sci 945: 172-178, 2001. PMID: 11708475. DOI: 10.1111/j.1749-6632.2001.tb03882.x

14 Silva JM, Rodriguez R, Garcia JM, Munoz C, Silva J, Dominguez G, Provencio M, Espana P and Bonilla F: Detection of epithelial tumour RNA in the plasma of colon cancer patients is associated with advanced stages and circulating tumour cells. Gut 50(4): 530534, 2002. PMID: 11889075. DOI: 10.1136/gut.50.4.530

15 Shih CL, Luo JD, Chang JW, Chen TL, Chien YT, Yu CJ and Chiou CC: Circulating messenger RNA profiling with microarray and next-generation sequencing: Cross-platform comparison. Cancer Genomics Proteomics 12(5): 223-230, 2015. PMID: 26417025.

16 Cole AR: PCTK proteins: The forgotten brain kinases? Neurosignals 17(4): 288-297, 2009. PMID: 19816065. DOI: $10.1159 / 000231895$

17 Charrasse S, Carena I, Hagmann J, Woods-Cook K and Ferrari S: PCTAIRE-1: Characterization, subcellular distribution, and cell cycle-dependent kinase activity. Cell Growth Differ 10(9): 611-620, 1999. PMID: 10511311.

18 Fagerberg L, Hallstrom BM, Oksvold P, Kampf C, Djureinovic D, Odeberg J, Habuka M, Tahmasebpoor S, Danielsson A, Edlund K, Asplund A, Sjostedt E, Lundberg E, Szigyarto CA, Skogs M, Takanen JO, Berling H, Tegel H, Mulder J, Nilsson P, Schwenk JM, Lindskog C, Danielsson F, Mardinoglu A, Sivertsson A, von Feilitzen K, Forsberg M, Zwahlen M, Olsson I, Navani S, Huss M, Nielsen J, Ponten F and Uhlen M: Analysis of the human tissue-specific expression by genome-wide integration of transcriptomics and antibody-based proteomics. Mol Cell Proteomics 13(2): 397-406, 2014. PMID: 24309898. DOI: $10.1074 / \mathrm{mcp} . M 113.035600$

19 Meyerson M, Enders GH, Wu CL, Su LK, Gorka C, Nelson C, Harlow E and Tsai LH: A family of human cdc2-related protein kinases. EMBO J 11(8): 2909-2917, 1992. PMID: 1639063. DOI: $10.1002 / j .1460-2075.1992 . t b 05360 . x$
20 Besset V, Rhee K and Wolgemuth DJ: The cellular distribution and kinase activity of the CDK family member pctaire 1 in the adult mouse brain and testis suggest functions in differentiation. Cell Growth Differ 10(3): 173-181, 1999. PMID: 10099831.

21 Graeser R, Gannon J, Poon RY, Dubois T, Aitken A and Hunt T: Regulation of the CDK-related protein kinase PCTAIRE-1 and its possible role in neurite outgrowth in neuro-2a cells. J Cell Sci 115(Pt 17): 3479-3490, 2002. PMID: 12154078.

22 Mikolcevic P, Sigl R, Rauch V, Hess MW, Pfaller K, Barisic M, Pelliniemi LJ, Boesl M and Geley S: Cyclin-dependent kinase 16/PCTAIRE kinase 1 is activated by cyclin y and is essential for spermatogenesis. Mol Cell Biol 32(4): 868-879, 2012. PMID: 22184064. DOI: 10.1128/MCB.06261-11

23 Palmer KJ, Konkel JE and Stephens DJ: PCTAIRE protein kinases interact directly with the COPII complex and modulate secretory cargo transport. J Cell Sci 118(Pt 17): 3839-3847, 2005. PMID: 12091426. DOI: jcs.02496 [pii]10.1242/jcs.02496

24 Liu Y, Cheng K, Gong K, Fu AK and Ip NY: PCTAIRE1 phosphorylates $\mathrm{N}$-ethylmaleimide-sensitive fusion protein: Implications in the regulation of its hexamerization and exocytosis. J Biol Chem 281(15): 9852-9858, 2006. PMID: 16461345. DOI: 10.1074/jbc.M513496200

25 Chen XY, Gu XT, Saiyin H, Wan B, Zhang YJ, Li J, Wang YL, Gao R, Wang YF, Dong WP, Najjar SM, Zhang CY, Ding HF, Liu JO and Yu L: Brain-selective kinase 2 (BRSK2) phosphorylation on PCTAIRE1 negatively regulates glucosestimulated insulin secretion in pancreatic beta-cells. J Biol Chem 287(36): 30368-30375, 2012. PMID: 22798068. DOI: 10.1074/jbc.M112.375618

26 Wang H, Liu H, Min S, Shen Y, Li W, Chen Y and Wang X: Cdk16 overexpressed in non-small cell lung cancer and regulates cancer cell growth and apoptosis via a p27-dependent mechanism. Biomed Pharmacother 103: 399-405, 2018. PMID: 29674275. DOI: 10.1016/j.biopha.2018.04.080

27 Yanagi T, Krajewska M, Matsuzawa S and Reed JC: PCTAIRE1 phosphorylates p27 and regulates mitosis in cancer cells. Cancer Res 74(20): 5795-5807, 2014. PMID: 25205104. DOI: 10.1158/0008-5472.CAN-14-0872

28 Jemal A, Bray F, Center MM, Ferlay J, Ward E and Forman D: Global cancer statistics. CA Cancer J Clin 61(2): 69-90, 2011. PMID: 21296855. DOI: 10.3322/caac.20107

29 Travis WD: Pathology of lung cancer. Clin Chest Med 32(4): 669-692, 2011. PMID: 22054879. DOI: 10.1016/j.ccm.2011. 08.005

30 Goldstraw P, Chansky K, Crowley J, Rami-Porta R, Asamura $\mathrm{H}$, Eberhardt WE, Nicholson AG, Groome P, Mitchell A, Bolejack V, International Association for the Study of Lung Cancer Staging and Prognostic Factors Committee, Advisory Boards, and Participating Institutions, and International Association for the Study of Lung Cancer Staging and Prognostic Factors Committee Advisory Boards and Participating Institutions: The IASLC lung cancer staging project: Proposals for revision of the TNM stage groupings in the forthcoming (eighth) edition of the TNM classification for lung cancer. J Thorac Oncol 11(1): 39-51, 2016. PMID: 26762738. DOI: $10.1016 /$ j.jtho.2015.09.009

31 Rosell R and Karachaliou N: Lung cancer: Maintenance therapy and precision medicine in NSCLC. Nat Rev Clin Oncol 10(10): 549-550, 2013. PMID: 23959270. DOI: 10.1038/nrclinonc. 2013.152 
32 Downey T: Analysis of a multifactor microarray study using Partek genomics solution. Methods Enzymol 411: 256-270, 2006. PMID: 16939794. DOI: 10.1016/S0076-6879(06)11013-7

33 Rhodes DR, Kalyana-Sundaram S, Mahavisno V, Varambally R, Yu J, Briggs BB, Barrette TR, Anstet MJ, Kincead-Beal C, Kulkarni P, Varambally S, Ghosh D and Chinnaiyan AM: Oncomine 3.0: Genes, pathways, and networks in a collection of 18,000 cancer gene expression profiles. Neoplasia 9(2): 166-180, 2007. PMID: 17356713. DOI: $10.1593 /$ neo.07112

34 Rhodes DR, Yu J, Shanker K, Deshpande N, Varambally R, Ghosh D, Barrette T, Pandey A and Chinnaiyan AM: Oncomine: A cancer microarray database and integrated data-mining platform. Neoplasia 6(1): 1-6, 2004. PMID: 15068665. DOI: 10.1016/s1476-5586(04)80047-2

35 Ravn V, Rasmussen BB, Hojholt L, Barfoed M, Heiberg I and Thorpe SM: Reproducibility of subjective immunohistochemical estrogen- and progesterone receptor determination in human endometrium. Pathol Res Pract 189(9): 1015-1022, 1993. PMID: 8302719. DOI: $10.1016 / \mathrm{S} 0344-0338(11) 80674-6$

36 Ravo M, Mutarelli M, Ferraro L, Grober OM, Paris O, Tarallo R, Vigilante A, Cimino D, De Bortoli M, Nola E, Cicatiello L and Weisz A: Quantitative expression profiling of highly degraded rna from formalin-fixed, paraffin-embedded breast tumor biopsies by oligonucleotide microarrays. Lab Invest $88(4)$ : 430-440, 2008. PMID: 18305565. DOI: 10.1038/labinvest. 2008.11

37 Setlur SR, Mertz KD, Hoshida Y, Demichelis F, Lupien M, Perner S, Sboner A, Pawitan Y, Andren O, Johnson LA, Tang J, Adami HO, Calza S, Chinnaiyan AM, Rhodes D, Tomlins S, Fall K, Mucci LA, Kantoff PW, Stampfer MJ, Andersson SO, Varenhorst E, Johansson JE, Brown M, Golub TR and Rubin MA: Estrogen-dependent signaling in a molecularly distinct subclass of aggressive prostate cancer. J Natl Cancer Inst 100(11): 815-825, 2008. PMID: 18505969. DOI: 10.1093/ jnci/djn150

38 Caby MP, Lankar D, Vincendeau-Scherrer C, Raposo G and Bonnerot C: Exosomal-like vesicles are present in human blood plasma. Int Immunol 17(7): 879-887, 2005. PMID: 15908444. DOI: $10.1093 /$ intimm/dxh267

39 Valadi H, Ekstrom K, Bossios A, Sjostrand M, Lee JJ and Lotvall JO: Exosome-mediated transfer of mRNAS and microRNAs is a novel mechanism of genetic exchange between cells. Nat Cell Biol 9(6): 654-659, 2007. PMID: 17486113. DOI: $10.1038 /$ ncb1596

40 Skog J, Wurdinger T, van Rijn S, Meijer DH, Gainche L, SenaEsteves M, Curry WT, Jr., Carter BS, Krichevsky AM and Breakefield XO: Glioblastoma microvesicles transport RNA and proteins that promote tumour growth and provide diagnostic biomarkers. Nat Cell Biol 10(12): 1470-1476, 2008. PMID: 19011622. DOI: $10.1038 /$ ncb1800

41 Zernecke A, Bidzhekov K, Noels H, Shagdarsuren E, Gan L, Denecke B, Hristov M, Koppel T, Jahantigh MN, Lutgens E, Wang S, Olson EN, Schober A and Weber C: Delivery of microRNA-126 by apoptotic bodies induces CXCL12-dependent vascular protection. Sci Signal 2(100): ra81, 2009. PMID: 19996457. DOI: $10.1126 /$ scisignal.2000610
42 Tsui NB, Ng EK and Lo YM: Stability of endogenous and added rna in blood specimens, serum, and plasma. Clin Chem 48(10): 1647-1653, 2002. PMID: 12324479.

43 Hong CS, Funk S and Whiteside TL: Isolation of biologically active exosomes from plasma of patients with cancer. Methods Mol Biol 1633: 257-265, 2017. PMID: 28735492. DOI: 10.1007/978-1-4939-7142-8_16

44 Shih CL, Chong KY, Hsu SC, Chien HJ, Ma CT, Chang JW, Yu CJ and Chiou CC: Development of a magnetic bead-based method for the collection of circulating extracellular vesicles. N Biotechnol 33(1): 116-122, 2016. PMID: 26409934. DOI: 10.1016/j.nbt.2015.09.003

45 Okamura K, Takayama K, Izumi M, Harada T, Furuyama K and Nakanishi Y: Diagnostic value of CEA and CYFRA 21-1 tumor markers in primary lung cancer. Lung Cancer 80(1): 45-49, 2013. PMID: 23352032. DOI: 10.1016/j.lungcan.2013.01.002

46 Coelho AL, Araujo A, Gomes M, Catarino R, Marques A and Medeiros R: Circulating Ang-2 mRNA expression levels: Looking ahead to a new prognostic factor for NSCLC [corrected]. PLoS One 9(2): e90009, 2014. PMID: 24587185. DOI: 10.1371/journal. pone.0090009

47 Gumireddy K, Li A, Chang DH, Liu Q, Kossenkov AV, Yan J, Korst RJ, Nam BT, Xu H, Zhang L, Ganepola GA, Showe LC and Huang Q: Akap4 is a circulating biomarker for non-small cell lung cancer. Oncotarget 6(19): 17637-17647, 2015. PMID: 26160834. DOI: 10.18632/oncotarget.3946

48 Yu XM, Wu YC, Liu X, Huang XC, Hou XX, Wang JL, Cheng $\mathrm{XL}$, Mao WM and Ling ZQ: Cell-free RNA content in peripheral blood as potential biomarkers for detecting circulating tumor cells in non-small cell lung carcinoma. Int J Mol Sci 17(11), 2016. PMID: 27827952. DOI: 10.3390/ijms 17111845

49 Wang Y, Qin X, Guo T, Liu P, Wu P and Liu Z: Up-regulation of CDK16 by multiple mechanisms in hepatocellular carcinoma promotes tumor progression. J Exp Clin Cancer Res 36(1): 97, 2017. PMID: 28716136. DOI: 10.1186/s13046-017-0569-2

50 Yanagi T, Reed JC and Matsuzawa S: PCTAIRE1 regulates p27 stability, apoptosis and tumor growth in malignant melanoma. Oncoscience 1(10): 624-633, 2014. PMID: 25593992. DOI: 10.18632/oncoscience.86

51 Yanagi T, Shi R, Aza-Blanc P, Reed JC and Matsuzawa S: PCTAIRE1-knockdown sensitizes cancer cells to TNF family cytokines. PLoS One 10(3): e0119404, 2015. PMID: 25790448. DOI: 10.1371/journal.pone.0119404 